or absence of dentures has much effect, except when the level is still very high. This may seem surprising, but a little consideration of the mechanism involved shows that it can be expected. The alcohol concentration of even a weak drink such as beer is several hundred times as high as that of the tissue fluids of even a very drunk man, so it is not surprising that traces in the mouth, pharynx, tonsils, and probably even the sinuses lead to very high breath readings immediately after drinking. This high figure falls exponentially so that the time taken to fall to a negligible level is not much affected by the nature of the drink, and is in fact 15 to 30 minutes.

Two mechanisms are involved in this fall, evaporation into the breath and diffusion through the mucous membranes. If alcohol is trapped under a dental plate it can still be absorbed, and if it cannot escape into the breath it cannot affect the breath alcohol level, so that dentures make very little difference. Alcohol on the surface of the dentures themselves will quickly evaporate, as they are nonabsorbent. Similarly, washing the mouth with water will not remove alcohol from the mucous membranes of the mouth much faster than the breath does, and will not affect the pharynx and sinuses at all. If the breath contains alcohol, mouth washing may give a spuriously low reading by cooling the breath, ${ }^{2}$ so from a legal point of view it is a practice to be deprecated.-I am, etc.,

$$
\begin{aligned}
& \text { Rickmansworth, } \\
& \text { Herts. }
\end{aligned}
$$$$
\text { B. M. WRIGHT. }
$$

REFERENCES

1 Begg, T. B., Hill, I. D., and Nickolls, L. C., 2 Wright, Bed. M., 1964, 1,9., in Alcohol and Road Traffic, 1963, p. 251, B.M.A., London.

\section{Accidental Poisoning in Children}

SIR,-We have reviewed the cases of children aged up to 12 years treated at this hospital for accidental poisoning in the period 1958-67. Dr. R. H. Jackson and colleagues (26 October, p. 245) report that in Newcastle $38 \%$ of such cases attending were admitted. At this hospital the proportion admitted from the casualty department rose from $63 \%$ of the 24 attendances in 1958 to $85 \%$ of 147 attendances in 1967. Hospital admission rates are inadequate indices for comparing the incidence of accidental poisoning in children in different areas. The majority of attenders $(95 \%)$ were under 5 years old. As in Cardiff hospitals ${ }^{1}$ the excess of males in the 1950s decreased till in 1967 the proportions of males and females were equal. The peak attendances, too, were in the second and third quarters of the year, but in Kettering this was an increasing trend.

Medicinal preparations formed the largest group of poisons $(66 \%)$; then household agents $(25 \%)$; and berries, seeds, etc. (8\%). Aspirin was the medicament most commonly taken, representing $35 \%$ of the consumption in 1967 when oral contraceptives (14\%) accounted for an increasing proportion.

The rate of attendance for accidental poisoning in the population at risk aged 0-4 increased from 1.8 to 7.3 per thousand between 1961 and 1967. During that period the boundaries of the catchment area were unchanged and the population at risk increased by one-fifth. No additional casualty department was opened in the area and the number of beds available for children did not increase. The increased rate of attendance partly reflects the increasing opportunities for consuming drugs like oral contraceptives and tranquillizers which are prescribed in increasing quantity, and partly changes in referring policy. For example, the proportion of cases accompanied by a letter from the general practitioner decreased from $14 \%$ to zero between 1958 and 1967, suggesting either that parents are increasingly referring their poisoned children to hospital without contacting their own doctor, or that the general practitioner is increasingly arranging for the parents to take the child to hospital when contacted, and is less likely than he might once have been to visit, observe, and send to hospital only the more severe cases. The latter was supported by our finding that the rate of referral for accidental poisoning from some general practices suddenly increased and remained higher in ensuing years.

Finally, proximity of the home address to the hospital was associated with a higher rate of attendance for accidental poisoning. Expected numbers of attendances were calculated for localities at varying distances in miles from the hospital, showing no marked differences on social and demographic indices. The observed number in the area nearest the hospital was nearly double that expected ; in an intermediate area the observed and expected numbers roughly coincided; and in the most distant area fewer than half the expected numbers attended. This perhaps reflects the tendency of parents and doctors to use a facility which is near at hand.-We are, etc.,

\section{R. WIGGLESWORTH. B. T. Williams \\ Kettering General Hospital,}

\section{REFERENCE}

1 Graham, J. D. P., and Hitchens, R. A. N., Brit. 7. prev. soc. Med., 1968, 22, 55 .

\section{Seasickness}

SIR,-Your leading article (19 October, p. 137) reviewing the annual report of the Royal Naval Medical School was of the greatest interest to us, for in Cunard we too have been actively concerned with the treatment of motion sickness and the problem of acoustic trauma in our ships' engine rooms. In spite of the advent of stabilizers and advanced hull design, seasickness continues to constitute a major problem, not only in passenger ships, but also in the crews of freight ships. Indeed, there is evidence to suggest that seasickness may well be increasing in cargo vessels, possibly owing to placing the living accommodation high above the waterline in the after portion of the ship, subjecting men to considerable magnification of the movement at main deck level amidship.

After very many trials we are firmly convinced that to date the most useful and effective drug available is promethazine hydrochloride. The preparation is active both orally and intravenously. The intramuscular route is by far the most effective in this context, and with trained medical personnel available on passenger ships administration constitutes no problem. Two years ago the medical department equipped our freight ships with intramuscular promethazine hydrochloride, disposable syringes and needles, together with instructions, on the basis that a master mariner is a man with a great deal of technical ability and responsibility and has for long been authorized to administer narcotics and antibiotics to sick members of his crew by intramuscular injection. The dangers of allowing patients to be exposed to situations where drowsiness would be hazardous were emphasized.

A dosage of $50 \mathrm{mg}$. intramuscularly is employed in adults, after which the patient is sent to bed for one hour, when he usually sleeps. The results are nearly always truly dramatic. Children are safely treated in the same mannes in a proportionate dosage. Upon waking they usually feel so well that they have entirely regained their appetite and are able to enjoy the shipboara menu to the full almost immediately. Remarkably, one such injection suffices in $95 \%$ of cases for the remainder of a transatlantic crossing, but during cruising, where passengers go ashore, it may be necessary to repeat the treatment if the liner meets rough water on a subsequent leg of the cruise. In cargo ships and tankers the results have proved equally beneficial and certainly one hour away from his station is to be preferred to several days of sickness at work where a man might endanger himself and his colleagues.

In the design of recent new tonnage the danger of exposing engineers to acoustic trauma and subsequent high-frequency deafness in engine-rooms has been recognized. Such exposure has a marked effect upon the accuracy of work and possible accident rate. Thus, throughout each phase of the design, building, and testing of these new ships, studies are centred on preventing operatives from being exposed to dangerous noise levels.

Gas turbines have not yet been found a place as power units in commercial shipping as they have in the Royal Navy, but should they do so in the future it seems likely that they will create special problems. On the other hand high-speed alternators are extensively used and their noise emission is frequently contained in soundproof bulkheads. When servicing this equipment the electricians wear ear protectives or close down the alternator, a situation which is made easier in practice by duplication of alternators in separate booths.-We are, etc.,

Robert M. Heggie,

Cunard Group Medical Consultant. IAN Reid ENTwistle,

Medical Consultant Cunard/Brocklebank Ltd. Liverpool.

\section{Severe Pneumonia in Young Children}

SIR,-In your leading article (2 November, p. 267) you rightly point out the need for early recognition of incipient symptoms that indicate the onset of peripheral vascular failure or of cerebral hypoxia. You suggest that the cases presenting at hospital with circulatory failure should be regarded as being in the same category as " cot deaths." If this is accepted the case fatality rate for the condition, or conditions, must be extremely high.

Many of the current investigations are concerned with the clinical and pathological conditions present, but there is another aspect which has not so far received much attention. In a recent study of the social circumstances of a small series of families in which there had been a "cot death" I found a large number of adverse factors present. The mothers had on the whole been poor users of available services, and of ten showed reluct- 